\title{
Student Psychological Factors and Diversity in Computer Science Education
}

\author{
Shasta Ihorn, Ph.D. \\ San Francisco State University \\ sihorn@sfsu.edu
}

\author{
Ilmi Yoon, Ph.D. \\ San Francisco State University \\ ilmi@sfsu.edu
}

\author{
Anagha Kulkarni, Ph.D. \\ San Francisco State University \\ ak@sfsu.edu
}

\begin{abstract}
Underrepresentation of women and Black and Latinx individuals in computer science (CS) is a well-documented issue facing university training programs and the field in general. In an effort to expand on current knowledge and help bridge the equality gap in CS, a pilot interdisciplinary Computing Applications minor program was started in 2016 at San Francisco State University (SFSU). The "Promoting INclusivity in Computing" (PINC) program was designed to improve diversity in computing and increase computing literacy in data-intensive fields, specifically biology and chemistry. Students participating in the PINC program were compared to lower division CS majors at SFSU on measures assessing their attitudes toward computer science, goal-setting tendencies, experience of stereotype threat, general self-efficacy, and computer science self-efficacy. Analysis showed that students in the PINC program reported lower levels of computer science self-efficacy, but there were no significant differences between groups on self-report measures of goal-setting tendencies, experience of stereotype threat, attitudes toward computer science, and general self-efficacy. These findings highlight the success of the minor program in creating an educational environment that supports the achievement of underrepresented (UR) students, as well as the similar psychoeducational traits of the two groups of students. Findings may be of particular interest to postsecondary CS teachers, researchers interested in social justice and representation issues as they pertain to the field of computing, and university and departmental administrators who wish to increase and promote diversity in their CS programs.
\end{abstract}

\section{INTRODUCTION \& BACKGROUND}

The CS field is one of the least diverse of the STEM disciplines, and retention of UR students has been an ongoing problem in CS

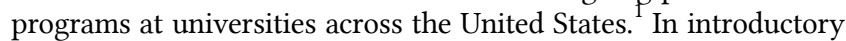
CS courses, the dropout rate for UR students is twice the dropout rate for male, Asian, and/or White students enrolled in the same courses. ${ }^{2}$ Further, the numbers of UR students earning degrees in computer science are much lower than what would be expected based on the proportion of these groups in the overall U.S. population. ${ }^{3}$ The shortage of women and individuals from certain racial and ethnic groups within the field of CS is concerning, as it contributes to systemic academic inequality, deprives the field of the diverse perspectives offered by these individuals, and may limit innovation. Previous research has demonstrated that psychosocial factors can contribute to this disparity. ${ }^{4}$ The PINC program minor in Computing Applications was initiated at SFSU in Fall 2016 jointly by the CS and Biology departments to improve

Permission to make digital or hard copies of part or all of this work for personal or classroom use is granted without fee provided that copies are not made or distributed for profit or commercial advantage and that copies bear this notice and the full citation on the first page. Copyrights for third-party components of this work must be honored. For all other uses, contact the Owner/Author(s).

SIGCSE'20, March 11-14, 2020, Portland, OR, USA

(C) 2020 Copyright held by the owner/author(s).

ACM ISBN 978-1-4503-6793-6/20/03.

https://doi.org/10.1145/3328778.3372671 diversity in computing while also increasing computing literacy in the increasingly data-intensive field of Biology. Since the program's inception, PINC enrollments have consisted of $70-80 \%$ female students and 40-50\% UR students. Program students complete five Computer Science courses in CS fundamentals and web programing, as well as a year-long interdisciplinary capstone project. To support students on this challenging academic journey, the PINC program provides substantial support in the form of cohort structure, peer- and near-peer mentors, and small class sizes. Overall, the academic experience of PINC students is very different from that of typical CS major students. This forms the motivation for the analysis of students' psychological traits presented here.

\section{METHODS \& RESULTS}

A Qualtrics survey link was distributed to students in a large, lower division CS survey course and to students in PINC program courses. A total of 227 students completed at least one component of the administered survey. Students participating in the PINC program were compared to lower division CS majors at SFSU on measures assessing their attitudes toward computer science, goalsetting tendencies, experience of stereotype threat, general selfefficacy, and computer science self-efficacy. Students in the PINC program reported significantly lower levels of computer science self-efficacy, but there were no significant differences between groups on self-report measures of goal-setting tendencies, experience of stereotype threat, attitudes toward computer science, and general self-efficacy.

\section{CONTRIBUTIONS \& FUTURE WORK}

These results indicate that PINC students (primarily UR and female students) are psychologically just as well prepared to succeed in a computing program as the CS major students (primarily white and Asian male students). This is an encouraging result for the PINC program, as it suggests that PINC students are thriving, and the support mechanisms of the program are serving their intended purpose. Future directions for research could include investigations into differences by gender and race in the CS major with regard to the variables of interest, as well as investigation into differences between students from UR groups and students from historically overrepresented groups within the PINC program itself. Further, analysis of PINC program components that contribute to the success of UR students would also be valuable.

\section{REFERENCES}

[1] Kulkarni, A., Yoon, I., Pennings, P. S., Okada, K., \& Domingo, C. (2018, July). Promoting diversity in computing. In Proceedings of the 23rd Annual ACM Conference on Innovation and Technology in Computer Science Education. ACM, Larnaca, Cypress.

[2] CSU Student Success Dashboard. (2019). Retrieved from https://csusuccess.dashboards.calstate.edu/public/db-where-do-they-struggle

[3] National Center for Educational Statistics. (2017). Digest of Education Statistics. Retrieved from https://nces.ed.gov/programs/digest/

[4] Rodriguez, S. L., \& Lehman, K. (2018). Developing the next generation of diverse computer scientists: The need for enhanced, intersectional computing identity theory. Computer Science Education, 27(3), 229-247. 